\title{
ESTUDOS SOBRE O PROCESSO DE DESVALORIZAÇÃO DO TRABALHO HUMANO DE ACORDO COM A LÓGICA EMPRESARIAL DO SÉCULO XXI
}

OLIVEIRA, L. J. de. Estudos sobre o processo de desvalorização do trabalho humano de acordo com a lógica empresarial do século XXI. Rev. Ciênc. Juríd. Soc. UNIPAR. Umuarama. v. 17, n. 1, p. 5-26, jan./jun. 2014.

RESUMO: Do estudo feito, concluiu-se que os avanços tecnológicos impuseram ao homem uma nova rotina de trabalho, mais intensa, reduzindo em demasia a possibilidade de existência de um tempo livre. A tendência é a geração de um trabalho fragmentado, precário, voltado somente à sobrevivência humana, encontrando-se em desacordo com os princípios constitucionais e por sua vez com os direitos sociais, que preveem um trabalho que possa contribuir com a redução das desigualdades sociais, com a emancipação do homem, enquanto dando-lhe condições de expor sua criatividade e de localizar-se no meio social como agente realizador. A expressão trabalho livre toma nova dimensão, enquanto sendo aquele trabalho que, contrariando a lógica do mercado, é suficiente para proporcionar ao ser trabalhador não somente a sobrevivência ou a existência precária, mas uma vida construtiva. A crítica à lógica da produção deve ser capaz de criar mecanismos de intervenção capazes de restabelecer a dignidade no trabalho.

PALAVRAS-CHAVES: Avanço tecnológico; Centralização do trabalho; Dignidade no trabalho; Humanização no trabalho.

\section{INTRODUÇÃO AO ESTUDO A RESPEITO DO TRABALHO HUMANO}

O avanço do capitalismo a partir da descoberta de novas técnicas para serem empregadas na produção dá origem a várias reflexões sobre o destino a ser trilhado pela humanidade. Muitas vezes tudo parece natural, quando na verdade trata-se de uma construção histórica e, portanto cultural, possível de ser transformada. $\mathrm{O}$ mercado de trabalho, assim como o mercado econômico não são entes imaginários formados naturalmente. Trata-se de construções feitas pelo homem, muito embora, por vários momentos queira transparecer como algo imodificável,

DOI: https://doi.org/10.25110/rcjs.v17i1.2014.5352

${ }^{1}$ Professor Doutor em Direito das Relações Sociais (PUC-SP); Professor do Curso de Mestrado em Direito Negocial da Universidade Estadual de Londrina; Professor do Curso Mestrado em Direito da Universidade Marília; Integra o corpo docente das seguintes instituições: Universidade Estadual de Londrina; Universidade de Marília; Faculdade Paranaense. Advogado em Londrina. Endereço eletrônico: lourival.oliveira40@hotmail.com 
que se rege por leis naturais.

Todas essas mudanças lançam cada dia mais um intenso debate sobre o trabalho. Mais propriamente o significado do trabalho no século XXI. Dentro de uma elaboração marxista, o trabalho é o que difere o homem do resto dos animais. O otimismo tecnológico é negado pelo desemprego, pelos baixos salários, pela exclusão social que se produz em relação à própria tecnologia. Atualmente três quartos da humanidade são privados de remédios capazes de curar doenças, da comunicação, da condição de seres humanos, o que significa que ainda existe uma grande distância para a chamada socialização da tecnologia.

Tem-se no planeta os países desenvolvidos que se utilizam de uma tecnologia bastante superior em relação à utilizada pelos países não desenvolvidos, o que faz com que o mundo seja dividido em papéis. Existe aquela parte que fornece a matéria prima, que absorve os restos de uma produção industrial, produzindo nestes locais um modo de vida que talvez não alcance a subsistência para aqueles que ali moram.

Portanto, a tecnologia espalhada pelo mundo não é homogênea. A própria durabilidade das mercadorias que são produzidas atualmente, quer seja pelo seu tempo de utilização, de funcionalidade, quer seja pelo modismo, se apresenta com períodos cada vez mais curtos. Trata-se da intensificação do consumo, enquanto elemento necessário para a sustentação do modo de produção capitalista.

Desse modo, a sociedade se mantém como um sistema produtivo manipulando até mesmo a aquisição dos chamados 'bens de consumo duráveis' que necessariamente são lançados ao lixo (ou enviados a gigantescos ferros-velhos, como os 'cemitérios de automóveis' etc.) muito antes de esgotada a vida útil (MÉSZÁROS, 2002, p. 640).

O interesse privado é o que se sobrepõe. Muitas vezes tem-se até mesmo a criatividade humana sendo freada pelos interesses de determinados oligopólios que dominam uma parte da produção científica, que não é livre e nem democratizada. Muita cura de doenças não é do domínio público por uma questão de interesses outros mais lucrativos, comprovando-se assim a sobreposição do interesse privado sobre o interesse público.

A indústria bélica hoje consome grandes recursos mundiais. Baron (2004, p. 144) afirma que os Estados Unidos são responsáveis pela metade dos gastos mundiais em armamentos, e mantém bases e missões de treinamento militar em 121 países do planeta. Mészários (2004, p. 285) aponta que o complexo militar-industrial controla $70 \%$ de toda a pesquisa científica dos EUA. Ao mesmo tempo, na Grã-Bretanha os índices percentuais correspondem a 50\%.

Marx afirmou que a tecnologia demonstra a forma de ação do homem sobre a natureza, como se produz a vida, e as suas condições sociais de vida, ao 
ponto de Einstein, anos depois, afirmar: "por que a ciência aplicada, que é tão magnífica, economiza trabalho e torna a vida mais fácil, nos proporciona tão pouca felicidade? A resposta é simples: ainda não aprendemos a utiizá-la adequadamente" (Apud, MÉSZÁROS, 2004, p. 288).

Dentro dessa análise desponta-se a importância do estudo sobre o trabalho, o seu significado na sociedade do século XXI, podendo apontar aqui duas linhas teóricas. A primeira que apresenta o trabalho como ponto de centralidade e a segunda que o coloca em um segundo plano, ou seja, descentralizado. No tópico que segue são apresentadas essas duas vertentes.

\section{DA CENTRALIDADE A NÃO CENTRALIDADE DO TRABALHO E AS INOVAÇÕES TECNOLÓGICAS}

Robert Cantil (apud, CASTEL, 1988) defende a ideia da necessidade de um novo pacto social (ou contrato social), com a construção de um "capitalismo mais humanizado", objetivando uma maior distribuição de renda. Os excluídos socialmente são aqueles que não têm emprego e condições de empregabilidade ou que se encontra em condições de subemprego. $\mathrm{O}$ individualismo cresce ao ponto de não ser sentido o coletivo. Dessa feita, o que se tem é uma crise do trabalho, de integração dos menos favorecidos no mundo do trabalho. Neste contexto, o trabalho passa a ser uma referência social e psicológica.

Mantendo-se o trabalho como centro, mas seguindo outra vertente, existem aqueles que o concebem como a alienação do homem. Vale citar Antunes Mészáros, Frigotto, Lucena, Gounet, Kuenser, Machado, Mello, Salm, Bihr, Saviani, dentre outros.

Os homens exercem o papel mais importante na produção e as riquezas existem. $O$ problema é que elas estão concentradas. $\mathrm{O}$ capitalismo produz as riquezas, porém não consegue distribuí-las. A construção do ser social, de acordo com Marx, está centrada no trabalho. Os laços sociais, a própria forma de existência humana está centrada no trabalho. A forma como se realiza o trabalho se produz o tipo de ser social. (GRESPAN, 2008).

Em um primeiro plano o trabalho é a relação do homem com a natureza. É a sua força natural confrontando-se com a natureza. Depois, ao mesmo tempo em que ele (homem) modifica esta natureza, se modifica também. Na primeira fase, o trabalho enquanto força natural, não se encontra desapropriado da pessoa humana. Na segunda fase ele se constitui como mercadoria a ser vendida por aquele que naturalmente a possui, construindo com isto a sua condição de vida.

A abelha realiza trabalho, assim como a aranha também realiza. No caso 
do homem, o trabalho nasce em um primeiro momento na sua cabeça, no seu inconsciente e depois se materializa. Esta forma de produzir o trabalho acaba por distinguir, dentro da teoria marxista, o homem dos animais, tornando o trabalho um produto social e não um simples produto natural, algo que acontece como força do acaso.

O trabalho, que deveria ser um meio voltado para a humanização, com os avanços tecnológicos (invenção das máquinas), passou a ser a forma de dominação, em que aqueles que detêm os modos de produção passaram a controlar aqueles que não possuem esses meios. A máquina, as variadas revoluções tecnológicas foi para o marxismo o grande ponto de transformação da sociedade, definindo inclusive a concentração de riquezas em detrimento de uma maioria. Esta é a própria expressão maior da coisificação do homem.

O modo de se vestir, a forma de o homem viver, de sentir, de gostar são construídas a partir do trabalho. É neste sentido que o trabalho contribui para a alienação humana. Seguindo Hegel, Marx escreve suas obras baseando-se naquele autor, que acaba diferenciando o homem dos animais, por conta dos seus anseios ilimitados. A alienação do homem é um processo histórico com sólidas relações com o trabalho. O produto do trabalho produzido pelo trabalhador the é estranho. Quando se tem a mercadoria, pronta e acabada, o valor do trabalho que a produziu desaparece, razão pela qual ela pode ser trocada por um valor determinado, valor este que foi construído por meio do mercado.

Não possuindo os meios de produção, os trabalhadores são obrigados a venderem suas forças de trabalho, sem mesmo saber aquilo que estão produzindo e o valor que este produto detém. Dessa maneira, os trabalhadores tornaram-se indiferentes em relação àquilo que produzem, desde que com a venda de sua força de trabalho consigam o necessário para a sua sobrevivência. Este talvez seja o significado maior para alienação.

A questão que se coloca é: mesmo com as inovações tecnológicas, o trabalhador continua necessário para a produção capitalista? Talvez seja o caso de se questionar até que ponto a tecnologia poderá avançar, ao ponto de não mais necessitar da mão de obra humana. Será isso possível? Será possível viver em um mundo que a mão de obra humana seja dispensável ou utilizada de forma mínima ao ponto de uma grande massa de trabalhadores, qualificados ou não serem dispensáveis?

Jeremy Rifikin (2007), posiciona-se no sentido que a tendência do emprego é chegar a um fim. Segundo o autor, os postos de trabalho que são extintos em face do avanço tecnológico não serão mais recuperados, e, ainda com a diversidade e a criação de novos postos de trabalho, com novas atividades a serem desenvolvidas pelos seres humanos, não será suficiente para atender toda a demanda por empregos. A automação gera maior produção, que acaba fazendo 
com que os preços dos produtos abaixem, tornando-os mais competitivos. Esta cadeia, que de certa forma traz vantagens para o consumidor, acaba por produzir a redução do emprego. Trata-se do aumento da produtividade sem a geração de emprego.

Kurs (1992) afirma que a luta de classes não é o motor de transformação da sociedade e sim o fetiche da mercadoria. Esses pensamentos ganharam valoração para fins de estudo com a crise do capitalismo do final da década de 60. Ao mesmo tempo, Habermas (1998) aponta a dificuldade do homem em se desvincular da racionalização crescente. Para este último autor, a linguagem e não o trabalho apresenta-se como o centro das relações humanas. A linguagem é o que possibilita dar nomes as coisas, tratando-se de um ato de consciência. O trabalho não seria tão importante, ele só acontece a partir de uma simbologia social, que se expressa por meio da linguagem. $\mathrm{O}$ trabalho tem como pressuposto a linguagem, que pressupõe a interação entre pessoas.

Habermans se contrapõe a Marx. Com o avanço do capitalismo, a ciência se transformou na principal força produtiva. A possibilidade de superação não está no trabalho e sim nas mediações construídas a partir de um agir entre das pessoas.

O capitalismo não precisa mais explorar o trabalho, por conta que as modificações ocorridas na organização de sua produção podem libertar o homem do trabalho (KURZ, 1992).

No modo de produção capitalista, a mercadoria e a democracia capitalista impossibilitam que todas as parcelas sociais sejam iguais. As lutas dos trabalhadores não superaram os conflitos de interesse que se manifestavam nas fronteiras da sociedade da mercadoria, sem procurar superá-la. Essas afirmações problematizam a própria intervenção dos trabalhadores no processo estrutural de crise do capitalismo. Ao reivindicar o fim do masoquismo histórico nas dimensões do trabalho concreto, realiza a crítica da estratégia dos trabalhadores em tempos de crise do emprego. Os trabalhadores passam a ter como utopia o que sempre denunciaram e repudiaram: a exploração e precariedade do trabalho humano. Utopias que passam a se materializar na luta pelo "direito" de serem explorados. O "direito" à venda da força de trabalho independente do desenvolvimento dos processos de mais-valia absoluta e relativa tão bem exploradas por por Marx e Engels em "O Capital (LUCENA, 2006, p. 51-63).

Surge dessa visão descentralizada do trabalho a estruturação de novas classes sociais, agora baseadas no tempo livre (GORZ, 1987), explicando assim o conceito de socialismo pós-industrial, que seria uma sociedade baseada no desperdício mínimo. Viver mais com menos. Trata-se de uma nova planificação da- 
quilo que se é produzido. Uma nova coordenação, reduzindo ao mínimo as atribuições dos homens e estendendo-se as atribuições autônomas. O Estado passa a ter um papel decisivo nesta emancipação humana. Deve haver uma superação do trabalho alienado, crescendo-se os incentivos para o trabalho cooperado.

Esta linha de pensamento ganhou muita expressão no Brasil, a partir de Ladislaw Dowbor, que lança luz em outras formas de prestação de serviços, realização de trabalho, que não a assalariada (que seria o maior exemplo de trabalho assalariado), como instrumento de superação da crise. Uma delas se da mediante da apropriação pela própria comunidade do processo de produção (DOWBOR, 2009).

\section{DIGNIDADE DO TRABALHADOR, O NOVO CENÁRIO GLOBALIZA- DO E OS PRINCÍPIOS CONSTITUCIONAIS}

Primeiramente precisa-se tentar conceituar globalização, que se diga, trata-se de uma tarefa bastante difícil. Contudo, rapidamente conceituando, para servir para o momento, globalização é um misto de realidade e ideologia. Parece que o homem é globalizante em seu instinto (no sentido de uniformizar comportamentos). Por meio dessa onda globalizante, o Estado se contrai e as políticas púbicas se desfazem sob o mito de que o público não presta. Nesse sentido, especialmente no Brasil, em meados da década de 90, criou-se um discurso que o público não presta e que a coisa pública deve ser vendida para que se construa a otimização a partir de processos de privatização. O que ninguém esperava é que a crise inaugurada de forma concreta a partir de setembro de 2008 tenha ocorrido pela liberdade que se deu ao mercado financeiro de se auto-organizar, ao ponto de hoje ser pacífico o entendimento que o mercado financeiro deva ser regulado.

A economia é privada e por meio dela monta-se o estudo de uma competitividade sem precedentes que tende a concentrar capital a ponto de eliminar os competidores e caminhar para a construção de monopólio. Principais condições para atingir este objetivo: 1) desregulamentação e liberdade de mercado sem interferência do Estado, salvo naquilo que interessa, como por exemplo, dificuldade de cumprir os pressupostos legais para a realização da greve ou a liberação da exploração das jazidas de petróleo desde que as empresas que se habilitem a explorá-las cumpra certos requisitos só possíveis de serem cumpridos pelas líderes de mercado; 2) liberdade de mercado com reservas de proteção alfandegárias; 3) destruição de armamento nuclear com exceção dos Estados que estão ampliando seu arsenal bélico (EUA e Inglaterra); e, 4) união de grandes empresas que atuam no mesmo setor da produção.

Neste último caso, com o referendo do Estado nacional, que apóia essas fusões, com a justificativa de constituir grandes empresas, se possível nacionais 
para enfrentar o mercado externo. Ocorre que se esquece, na maioria das vezes, a questão da liberdade de mercado, por conta de acabam formando grandes monopólios em determinados setores da produção, controlando preços e tornando praticamente indefeso os consumidores.

E como se encontra a organização do trabalho (ou divisão do trabalho) neste mundo globalizado? As empresas se redimensionaram, alterações são feitas todos os dias, sempre em busca de melhorar a produtividade e aumentar a competitividade. O trabalho imaterial e criativo ganha peso por conta de que a máquina já está podendo fazer o resto.

Resta saber quantos trabalhadores criativos serão necessários para atender as necessidades deste novo modo de produção. Isto porque, outro processo que está ocorrendo é a concentração de atividades sobre a mesma pessoa, o que torna possível afirmar que haverá desemprego também para os qualificados criativos.

Claude Javillier (1998) consagrou a expressão "flexibilização de adaptação", que não pode ser confundida com a flexibilização e desregulamentação da forma como muitas vezes é colocada, quase como sinônimo do contratualismo que imperou na Inglaterra pós-Revolução Industrial. A questão da flexibilização, proposta neoliberal , muitas vezes, em se tratando de relações de trabalho, pode ser a porta de entrada da desregulamentação.

A dignidade da pessoa humana é a base da República (artigo $1^{\circ}$ da C.F). O Estado Democrático de Direito está assentado na limitação do Estado pelo Direito e na legitimação do poder político pelo povo. Os direitos sociais, caso sejam fundamentais também são inalteráveis. Para Ives Gandra Martins (1998), a Constituição apenas declara os direitos fundamentais, ela não os constitui (preexistem à própria Constituição). É possível afirmar que os direitos fundamentais e econômicos compõem o que se convencionou chamar de cidadania social e econômica, que nada mais é que uma nova concepção do conceito de cidadania. Depois o mesmo autor apresenta a chamada "teoria da justiça", que nada mais é que o Arrigo $6^{\circ}$ da Constituição Federal complementado com o artigo 170 da mesma carta, que seriam os resultados a serem alcançados.

Para Bobbio (1992), os direitos individuais traduzem-se em liberdades, exigindo-se obrigações negativas dos órgãos públicos, ao passo que os sociais se constituem em poderes, somente sendo realizados por ações positivas. Desta feita, seguindo as lições de Canotilho (2007), ainda que por meio de um poder constituinte originário, não se pode construir uma Constituição num vácuo histórico-cultural.

A construção de uma constituição está vinculada a valores e princípios internacionais, que se contrapõe ao que era pregado quando da Revolução Francesa, em que o poder de constituir tinha uma espécie de atributo divino (que era 
a ideia da onipotência constituinte). Daí surge a necessidade da observância dos princípios de justiça suprapositivos ou supralegais como limitadores da liberdade de constituir. Um poder constituinte não pode se dissociar da observância dos direitos humano.

Segundo Oscar Vilhena Vieria (1999) só é possível pensar a constituição levando-se em consideração o seu valor ético. Sendo assim, até cláusulas "petreas" seriam modificáveis quando em desacordo com os princípios da dignidade da pessoa humana.

Conforme já afirmado anteriormente, a economia baseia-se em fatores privados, em que o que conta é a lógica do lucro e não a satisfação das necessidades sociais. Segundo Keynes, o volume de emprego é que determina o nível dos salários reais. O que significa que o Estado deve coordenar os investimentos porque os juízos privados estão exclusivamente voltados para o "lucro privado". E esse pensamento reinou na Europa até o início da década de 70. Ou seja, se queria combater o desemprego e promover o emprego, bastava ter inflação; se quisesse baixar a inflação, deveria sujeitar-se ao crescimento do desemprego. (apud, NUNES, 2003, p. 4 a 8)

Ocorre que a contar da década de 70 na Europa, teve-se uma subida dos preços (elevação da inflação) com taxa de desemprego elevando-se também. Daí em diante a inflação foi eleita o inimigo número um do emprego, que devia ser combatida com vistas ao pleno emprego. Essa nova teoria, chamada de monetarista, explicava o desemprego enquanto sendo algo voluntário. Ou seja, o trabalhador está desempregado por uma opção sua, ainda que diante da existência de empregos cujos salários não atendam suas necessidades. Para a teoria monetarista, o trabalhador é visto individualmente, o que explica o combate às organizações sindicais.

Para os monetaristas, os sindicatos são os responsáveis pela queda do número de empregos. E o crescente desemprego, quando questionado, explica-se pelo aumento natural do desemprego, resultado da evolução demográfica, da derrota das economias, como se a pobreza fosse algo natural, e que pode ser combatida através da redução salarial, compatibilizando os custos de produção a fim de viabilizar a continuação do empreendimento privado. O que vale é a continuação do empreendimento privado, ainda com desemprego, a fim de que ele se recupere, recuperando assim o fluxo de emprego. Esse raciocínio, com algumas variações, é o que está hoje sendo empregado no Brasil e nas propostas econômicas internacionais, com investimentos públicos para salvar empreendimentos privados.

Para alguns fisiocratas (Dupont de Nemours principalmente), o aumento das riquezas traz necessariamente o aumento das desigualdades sociais. A aquisição da propriedade exclusiva de uma coisa gera uma exclusão em relação 
às demais pessoas (François Quesnay). A desigualdade econômica é considerada uma característica inerente às sociedades burguesas, apesar de terem vindo proclamar que todos os homens são livres e iguais perante a lei (NUNES, 2003).

A economia política, surgida com o capitalismo justifica a miséria como algo natural, legítimo, inerente às coisas, como que uma lei natural e absoluta. Keynes se opunha ao fato de que a miséria deve ser encarada como algo natural. As economias precisam ser equilibradas, devendo o Estado assumir referida tarefa. Daí por que devem ser preservados os consumos de massas. O subsídio às doenças e a previdência estatal, que se traduz no chamado Estado Providência (1930) (NUNES, 1988).

O próprio Adam Smith, em suas reflexões afirma que o contrato de trabalho não é um contrato com os outros porque ao trabalhador falta a liberdade para contratar. $\mathrm{O}$ maior dos liberais pressupunha a diferença fática para contratar quando o objeto era o trabalho, transcendendo assim a igualdade puramente jurídica.

Dessa feita, o evoluir tecnologicamente não está fazendo com que na mesma proporção seja diminuída a pobreza. É preciso uma reorganização social. Torna-se necessária a construção da crítica ao desenvolvimento disforme, o surgimento de novas formas de relações sociais de produção. Deve haver a negação da ciência do progresso, a não ser que esteja ela voltada ao crescimento do ser humano. O progresso econômico não significa necessariamente avanço social, e, a partir desta premissa, reorientar as formas de prestação de trabalho.

Caso assim não faça, a lógica da produção atual imporá a cada dia mais a redução de custos operacionais, trazendo grandes sacrifícios sociais para aqueles que verdadeiramente produzem, no caso, os trabalhadores. O processo de automação extingue postos de trabalho, as representações sindicais são esfaceladas pela crise, sobrando para o trabalhador arcar com o restante dos custos empresariais.

\section{O SIGNIFICADO E O ALCANCE DO ARTIGO 170 DA CONSTITUIÇÃO FEDERAL}

É difícil não debater, em um primeiro momento, da aproximação entre a economia e o Direito. Basta dizer da valoração normativa que o Direito atribui a uma diversidade de fenômenos econômicos. Atualmente, grandes evoluções tecnológicas, que possuem repercussões econômicas, são objetos de estudos e tentativas de regulamentação pelo Direito, o que significa que a Economia e o Direito são indissociáveis.

Basta dizer que qualquer agente econômico, como exemplo, uma grande montadora, estará disposta a instalar sua fábrica neste ou naquele país, levan- 
do-se em conta as condicionantes normativas (limites jurídicos impostos) para aquela localidade, em especial no que se refere às proteções sociais. Caso em uma determinada localidade exista normas de ordem pública que atribuem aos trabalhadores determinados direitos, a empresa que ali se instalar saberá que terá um custo adicional para somar ao valor do seu produto final. Efetivamente é desta maneira que economicamente se visualiza o valor empresarial despendido com os trabalhadores que diretamente laboram naquela determinada atividade empresarial.

Como os problemas são atualmente enfrentados no plano da economia? Vale citar João Sayad: Vivemos uma sociedade de quantidades, de números, que imagina que conhece ou pode conhecer tudo, rigorosamente e exatamente. Quanto mede quanto pesa, quanto custa e quanto vale são as perguntas mais importantes. (apud, COSTA).

Os argumentos econômicos se destacam dos argumentos normativos. Os argumentos normativos dizem respeito ao que poderia ser. São impregnados de valor, confrontando-se argumentos filosóficos, religiosos, culturais e etc. Os argumentos econômicos dizem respeito ao que foi ao que é e o que poderá vir a ser. Pelo menos, caso abstenha a economia do seu dever ético.

Tudo parece indicar que atualmente na prática, o que está prevalecendo é o posicionamento positivo, aqui empregado no sentido de econômico. Dessa feita, propõe-se a tentativa de libertar a economia de uma influência hegemônica dos paradigmas mais apropriados às ciências físicas, partindo-se para uma formulação do dever ser, à semelhança do Direito, na medida em que a ela deve-se agregar o conteúdo ético.

Contudo, deve-se também tomar cuidado que o Direito não pode assumir o papel de querer normatizar a economia, de tal maneira a desconsiderar a realidade econômica existente (lembrar dos insucessos dos planos econômicos). Da mesma forma, precisa ser levado em conta o equívoco cometido pelos positivistas que viam o Direito com certa simplicidade, como uma rede hierarquizada e formal de normas. As estruturas lógico-normativas do positivismo de Kelsen desconsideraram a trajetória móvel do Direito no mundo dos valores, podendo ter surgido daí o convencimento que a norma é capaz de regular a economia.

Daí recai a preocupação maior do intérprete com o fim buscado pela lei e não, com a sua vontade. É hierarquizar os princípios na sua interpretação. O Direito é um sistema aberto, razão pela qual ao intérprete caberá a busca pelo maior significado no caso concreto, superando as antinomias, a partir das confrontações teleológicas, tendo em vista a solução de casos concretos. Para Juarez Freitas (2004), a norma não pode ser interpretada separada dos fatos.

Tem-se então a concepção defendida por Miguel Reale, para quem o Direito não é só fato, ou só, valor ou só norma, estes três elementos integrados na 
experiência jurídica, estando todos dialeticamente correlacionados.

As normas jurídicas, longe de serem mera captação do que no fato já se contém, envolve uma tomada de posição opcional e constitutiva por parte do homem, à vista do fato e segundo critérios de valores irredutíveis ao plano da faticidade...". Mister é reconhecer que a norma jurídica permanece sempre em uma situação tencional (REALE, 1978, p. 79).

Voltando-se para o dilema Direito e Economia, aparece a questão do desenvolvimento. O crescimento econômico é desenvolvimento? Alguns autores apontam que crescimento econômico deve estar relacionado com melhoria da qualidade de vida e com liberdade para que se tenha desenvolvimento. Crescimento econômico é diferente de desenvolvimento econômico e a partir dessa constatação, começa-se a colocar no desenvolvimento econômico a necessidade de se alcançar o desenvolvimento social, o que pode ser chamado também de conteúdo ético.

Por essa razão principal é que indicadores como renda "per capita", produto nacional", quantidade de exportação não podem medir o desenvolvimento econômico. Questões como verificação de níveis de pobreza, do desemprego, da desigualdade social, da qualidade da moradia, da qualidade da educação e atendimento público à saúde podem propiciar a aquilatação do desenvolvimento econômico.

Na Constituição Federal, quando se examina o Capítulo II em sua totalidade, a melhor interpretação que deve ser extraída é a seguinte: na compreensão de desenvolvimento econômico devem estar contido os elementos qualidade de vida, bem-estar social, alcance efetivo da dignidade da pessoa humana.

Esta é a interpretação constitucional que se deve fazer no que diz respeito à leitura econômica, dentro de uma análise sistêmica, que se faz a partir do artigo 170 da Constituição Federal, de tal forma a compreender a economia não a partir de uma lógica exata e sim a partir de uma lógica humana. Segundo a concepção constitucional, a ordem econômica deve propiciar maior liberdade às pessoas, que se dá quando o desenvolvimento econômico é usufruído da forma mais ampla possível pela sociedade, não podendo significar um mero crescimento da renda "per capita" ou apropriar-se de outros indicadores isolados.

É neste sentido que a economia deve ser entendida, para juntamente com o Direito, estabelecer novos padrões para a produção, em que o investimento em qualidade de vida dos trabalhadores passa a ser algo importante, assim como os produtos resultantes de um processo que teve como pontos fundamentais ações que se prenderam a questões que contribuíram para a defesa dos valores humanos e sociais. Trata-se da humanização do próprio mercado, a partir de 
condutas econômicas éticas.

\section{OS PRINCÍPIOS CONSTITUCIONAIS, A NECESSIDADE DA PRESER- VAÇÃO DA LIBERDADE NO TRABALHO E O MODO DE PRODUÇÃO CAPITALISTA DO SÉCULO XXI}

Em um primeiro momento, para o leitor mais desavisado, passa a ideia que todos os preceitos de natureza econômica encontram-se contidos no Capitão I do Título VIII da C.F. E não é bem assim. Em segundo lugar, o artigo 170 da C.F. está diretamente ligado ao artigo $3^{\circ}$ da C.F., e aqui será dada maior ênfase à questão da valoração do trabalho humano.

Discute-se a moderna relação de trabalho. Tem-se então: a-de um lado o mundo globalizado, exigindo redução de custos e aumento da produtividade, fazendo com que se busquem novas formas de relações laborais (que em regra são mais fragilizadas em termos de direitos para os trabalhadores); b-também se encontram as empresas menores, que se acham tão fragilizadas quanto se acham os trabalhadores; c-o Direito Previdenciário, com os sistemas públicos em situação bastante difícil.

Dentro deste diálogo, muitas vezes contrapostos, surge a seguinte indagação: Como se valoriza o trabalho humano? Para responder de forma didática e com a maior objetividade, usou-se aqui apropriar dos seguintes parâmetros: a-que o trabalho seja livre, liberdade aqui no sentido de o ser humano ter várias oportunidades e possibilidades de trabalho; b-que o trabalho seja de qualidade, entendo-se como tal aquele em que o ser trabalhador possa se expressar por meio dele. Trata-se de um trabalho que mostra a importância do seu agente trabalhador perante a sociedade.

Esta concepção está voltada para a centralização do trabalho, que de certa forma apropria-se de conceitos marxistas, porém, buscando ações que possam revelar o trabalhador, a fim de que se situe dentro do fluxo da produção enquanto ser valorado. Trata-se do trabalho a partir de um novo conceito de vida ou da vida a partir do trabalho valorado.

Ao mesmo tempo não se pode perder de vistas no plano normativo o artigo $1^{\circ}$, IV e o artigo 193, ambos da Constituição Federal. Dentro desta ótica conclui-se que: constitucionalmente não é possível apreender o conceito de trabalho dentro de uma visão meramente patrimonialista. Também significa que o trabalho não é somente um fator de produção.

Por essa razão é que o trabalho está estruturado sob a forma de contrato, sem, contudo, ser um simples contrato, tendo por objeto a força de trabalho, por conta que não se trata de um objeto descartável e medido apenas patrimonialmente. Por meio do trabalho se expressa a vida e produz-se o homem. 
Justificado assim fica, normativamente, a proteção dispensada pelo sistema normativo ao trabalhador. De forma mais simples: o próprio princípio protetivo do Direito do Trabalho em relação ao ser trabalhador e ao ser que ainda não tem seu trabalho.

Voltando-se a mesma indagação. Como se valoriza o trabalho? Em um primeiro momento, mediante a geração de mais postos de trabalho; que haja um melhor trabalho com mais satisfação, com menos riscos, com mais criatividade, com a participação de quem trabalha no gerenciamento empresarial, sem discriminação; que seja melhor retribuído, com a efetivação dos direitos sociais consubstanciados nos artigos $6^{\circ}$ a $11^{\circ}$ da C.F.; que haja uma efetiva política pública de qualificação da mão de obra, capacitando criativamente o ser humano.

Outra questão que importa no estudo dos princípios e que se encontra contido no artigo 170 da Constituição Federal, que trata da livre iniciativa. A livre iniciativa se constitui em um dos fundamentos da ordem econômica, como o direito que todos possuem de investirem no mercado de produção de bens ou serviços por sua conta e risco.

Nesta esteira, novamente se faz necessária presença do Estado para garantir essa livre iniciativa? A livre iniciativa trata-se da principal marca do Estado capitalista. Prende-se também ao direito de propriedade.

Para se estudar a livre iniciativa não pode ser perdida a finalidade da ordem econômica, da forma como foi apreendida pela Constituição Federal. Ou seja, que tem por finalidade a existência digna. Dessa feita, cria-se uma grande condicionante da autonomia privada, que é a de agir com respeito aos valores substanciais ligados à pessoa humana.

Na parte final do artigo 170 da Constituição Federal tem-se: "conforme os ditames da justiça social”. Em outras palavras, a justiça social como fim da ordem econômica. E o que é justiça social? Sem querer ser repetitivo, evitar que os ricos se tornem mais ricos e os pobres mais pobres, buscar o aperfeiçoamento do Estado de Direito, e, que o verdadeiro desenvolvimento deva implicar em melhores condições de vida.

Sendo assim, não cabe qualquer acertiva sobre a eventual possibilidade de confronto de princípios constitucionais, no caso a livre iniciativa e a valorização do trabalho humano. A Constituição Federal consagra o princípio básico da ordem capitalista, que é a iniciativa privada, e, ao mesmo tempo, da prioridade de valores do trabalho humano sobre os demais valores. Conjugando os dois princípios, a liberdade econômica só deve existir e ser exercida quando no interesse da justiça social, o que implica necessariamente na presença do Estado regulador e interventor.

Cabe citar neste momento do trabalho os ensinamentos de Eros Grau. A Constituição Federal consagra um regime de Estado organizado, com a defesa 
da livre iniciativa, admitindo-se a sua intervenção para: a - coibir abusos; b- preservar a livre concorrência; c-evitar a formação de monopólios; d-evitar o abuso do poder econômico. A Constituição Federal contempla a economia de mercado: a-repudia o dirigismo estatal; b-a Constituição é capitalista, sendo que a liberdade de mercado só é admitida enquanto exercida no interesse da justiça social (GRAU, 2005).

Em outras palavras, o que ocorre é a necessidade de serem transplantados os princípios contidos nos artigos $1^{\circ}, 3^{\circ}, 5^{\circ}$, do $7^{\circ}$ aos 11 , artigo 24 , I, artigo 37, XIX, todos da Constituição Federal, para obter-se a interpretação do conteúdo transcrito no artigo 170 também da Constituição Federal, a fim de que se torne possível entender a ordem econômica segundo a Constituição Federal.

Resta por último indagar sobre a incoerência do atual modo de vida, criado a partir da exploração do trabalho humano e os princípios que norteiam a Constituição Federal, passando pela crítica às inovações tecnológicas, segundo o modelo imposto internacionalmente a partir do final do século XX. Em outras palavras, unir o que até aqui foi dito, de forma crítica e construtiva, de forma a entender o que está acontecendo com o trabalho humano no Brasil e no mundo.

Como se falar em dignidade no trabalho a partir dos paradigmas que são construídos para o trabalho humano. As premissas existentes para o trabalho humano são: o máximo de exploração com o emprego do menor número possível de trabalhadores, conseguindo-se o máximo de produtividade. Trata-se do pensamento econômico sem ética.

As defesas que se faziam em que a tecnologia poderia libertar o homem do trabalho, dando a ele condições de ter um maior tempo para o lazer, para a sua família acabou se perdendo em face da dura realidade atualmente vivida. Em outras palavras e parafraseando a historiadora Marilena Chauí, "o sonho acabou”. (CHAUÍ, 2000).

Com o progresso tecnológico, tornou-se mais distinto, principalmente após a II Grande Guerra Mundial (1950), a diferença entre empregar a tecnologia de forma criativa e empregá-la de forma destrutiva. Também, começou a despontar o significado de avanço científico, tecnológico, aumento do consumo e felicidade social ou desenvolvimento humano. O consumo de determinado aparelho doméstico, por exemplo, em um primeiro momento criou a utopia da felicidade ou da realização pessoal, que aos poucos desaparecia, talvez pela facilidade que foi sendo construída do acesso àquele mesmo aparelho, ou, pelas inovações que se apresentavam, criando novas ansiedades e novos desejos.

Desta feita, a "manipulação" sofrida a partir do trabalho se estende para a manipulação quanto ao que consumir, dando por assim dizer início a uma sociedade de massa, criando por assim dizer uma espécie de tentativa de uniformização contínua, vencendo diferenças culturais, históricas e expandindo-se sem 
limites de fronteiras, no que se traduz na expressão imposição de modo de vida.

Tem-se uma construção que já vinha do século XIX, em torno do trabalho assalariado, crescendo para uma paixão desmedida pelo trabalho, como se o trabalho representasse a própria essência do ser humano, que não pode existir sem que esteja trabalhando. Tal concepção contou em grande parte com doutrinas religiosas, sem aqui entrar a fundo no estudo dessas variadas doutrinas.

Dessa paixão pelo trabalho, tiveram-se as seguintes situações concretas: a necessidade da dupla jornada, que foi crescendo no mesmo compasso em que os salários foram reduzidos; a participação da mulher de forma maciça no mercado de trabalho, como que com isso houvesse a sua libertação, inclusive de ordem sexual; a polivalência do trabalhador como sinônimo de algo moderno e qualificado, sem falar aqui de outros exemplos clássicos que se seguiram, a partir do momento que o trabalho passou a ser o principal objetivo a ser alcançado.

Ocorre que dentro do trabalho, tem-se a sua própria classificação. Em um primeiro plano vem o trabalho permanente, aquele trabalho estável, que pode promover a tranquilidade de sobrevivência. E, o trabalho fragilizado, que no caso se encontram aqueles que se sujeita a iniciativa privada no Brasil, na maioria das vezes, onde incessantes processos de adaptação e de reengenharia consomem ou modificam postos de trabalho, tornando-o fragmentado, de curta duração e mal remunerado.

O homem do século XXI quer ter um trabalho de qualidade, considerado como tal aquele trabalho cuja fonte é estável, exemplificado como o trabalho advindo do setor público em determinadas carreiras para o caso brasileiro.

Acontece que impregnado por todo este culto ao trabalho, hoje, muito mais do que nos séculos XIX e XX, o ser trabalhador se aliena, se individualiza, se consome e se torna ignorante do seu próprio ser social que representa. Ao mesmo tempo em que a busca do trabalho de boa qualidade guarda no seu interior a busca pela melhoria das condições de vida do trabalhador, não percebe o próprio trabalhador que já se encontra na maioria das vezes exercendo um trabalho que lhe rende a miséria, o sofrimento, não lhe produzindo qualquer reconhecimento social ou bem-estar.

A expectativa de uma melhor condição de vida, para a grande massa de trabalhadores, acaba ficando só na expectativa, posto que por meio do trabalho, cada vez mais se afere somente o necessário para uma subvida.

É a racionalização extrema do trabalho, que pode ser sentida quando se abate as chamadas crises econômicas financeiras, em que os primeiros resultados concretos formam a extinção de postos de trabalho ou a redução da qualidade no trabalho, precarizando-se mais ainda aquilo que já se encontrava precário.

A teoria marxista, já citado neste estudo, compreende que o poder libertador advirá do trabalho, na medida em que a classe trabalhadora é o sujeito que 
detém o poder de transformar a sociedade. O proletariado seria por assim dizer o sujeito para criar uma nova sociedade, uma nova forma de se prover a vida. Agora, a questão que se coloca é: como alcançar este intento dentro da condição que hoje se encontra o trabalho, em especial pela sua substituição do trabalhador pelas máquinas?

Estas máquinas conseguem produzir por menores custos, contribuindo assim fortemente para um crescimento quantitativo do número de mercadorias e bens que são encontrados no mercado. A superprodução acaba por influenciar ainda mais no mercado de trabalho, que de certa forma torna-se a viga mestra que embala um novo sonho: o de que somente com muita produção e acelerando-se o consumo se constrói uma sociedade menos desigual e mais livre. Em outras palavras, que o crescimento econômico é o fator necessário para a liberdade humana.

Ocorre que este crescimento econômico é acolhido e realizado por meio de processos que estabelecem uma lógica despida de valor ético.

$\mathrm{Na}$ verdade, que se desperta com essas afirmativas é a pura intenção do lucro, da maior concentração de capital, das antigas recomendações feitas por economistas, agora presos e transmudados para conceitos voltados à era da modernidade. Talvez possa ser afirmado, sem qualquer cientificidade, que se está para atingir o maior nível de exploração nunca visto na história da humanidade. Até que ponto a crise econômica atual (2008-2009) não foi construída como parte dessa articulação de super-exploração do trabalho humano? O resultado maior desta chamada crise financeira já ocorreu e afetou em demasia as condições em que o trabalho humano é prestado, de forma que o trabalho que passou a ser produzido perdeu ainda mais a sua condição de valorizar o trabalhador.

Este tipo de trabalho que se está produzindo atualmente vem em descompasso aos principais princípios que nutrem a Constituição Federal, em especial a respeito da organização econômica (artigo 170). Referidos princípios são contrários à obsessão pelo trabalho. $\mathrm{O}$ homem não vive para trabalhar. Da forma como o trabalho encontra-se colocado, não dá espaço para qualquer outra atividade humana a não ser o trabalho em tempo integral, não restrito às 08 horas diárias, considerando as duplas jornadas, o duplo emprego, as rotinas "free lance" e outros modos de prestação de serviços. Como então produzir a consciência social partindo-se dessa situação de abnegação total ao trabalho? Como pensar, como criar, como interagir socialmente de forma criativa, de acordo com os novos métodos ou padrões de produzir que são colocados?

Parece que agora sim está se vivendo de fato a alienação humana de forma completa, se é que pode ser empregado este termo. O trabalho pela sobrevivência e o medo do desemprego, castrando qualquer perspectiva do trabalhador de promover os seus anseios como ser humano, se é que vai lhe sobrar algum outro anseio a não ser a sua sobrevivência para continuar podendo vender a sua 
força de trabalho. Como falar em humanização em um tempo em que o esforço pela sobrevivência é cada vez mais cobrado?

Fala-se em como preservar a liberdade no trabalho ou a busca da liberdade no trabalho dentro do modo de produção atual. Primeiramente, talvez não deixar que todo o esforço do ser humano seja empreendido no trabalho para sua sobrevivência. A ele seja reservado um tempo, o que implica na redução das jornadas de trabalho. Sem que haja tempo, como produzir algo? Como refletir socialmente? Os gregos antigos presumiam a necessidade de abolir o trabalho daqueles que pensam para que pudessem pensar.

É o sentido contrário daquilo que se está construindo atualmente no mundo do trabalho. Primar pela valorização da arte, da música, da filosofia, mudar o trato que se dá às informações que são recebidas. Estes são os primeiros passos para a libertação do homem do julgo do trabalho.

Existem aqueles que ainda defendem a possibilidade de associar o trabalho, só que não qualquer tipo de trabalho, a algo prazeroso e criativo, com a consequente geração por certo de um tempo livre, em face do incremento da tecnologia. Porém, o tempo livre é a base para a geração deste trabalho criativo, que diante da rotina empresarial empregada, está cada vez menor. Ou, misturar o trabalho com o lazer, o estudo, de tal maneira que não se soubesse quando começa um ou termina o outro. (DE MASI, 2000). A grande questão é que não é mais possível que a vida fique contida somente no trabalho. Para tanto, deve-se buscar a reorganização do que hoje é apresentado, um novo modelo de vida, que possui como premissa a existência de um tempo livre, podendo ser chamado de um trabalho inteligente.

O trabalho constitucionalmente apreendido, pressupõe este tempo livre, a partir do momento que pro meio dele deve-se, por exemplo, prover o lazer, na forma como se encontra no artigo $7^{\circ}$, IV da Constituição Federal. Ou ainda, quando no artigo 226, estabelece a família como base da sociedade, sob a proteção do Estado. Como manter laços familiares sem a existência de um tempo livre? Como realizar a assistência à criança sem a existência de um tempo livre?

Tem-se nos dias atuais um verdadeiro culto ao trabalho, sendo tomado como o único espaço existente na vida, impedindo outras manifestações sociais e sendo desta forma inconstitucional. $\mathrm{O}$ trabalho somente como fator de produção é inconstitucional, o que significa que deve haver uma mudança urgente na atual lógica da produção.

\section{CONSIDERAÇÕES FINAIS}

O trabalho encontra-se erigido em uma das ferramentas ou meios voltados à humanização, à realização do homem, talvez uma das poucas possibili- 
dades de se reduzir as desigualdades sociais, de forma a construir uma sociedade solidária.

No entanto, da forma como ele está sendo realizado, partindo-se da própria compreensão das estruturas empresariais atualmente existentes, percebe-se que os principais objetivos buscados por meio do trabalho é a máxima exploração do trabalhador, utilizando-se para tanto das novas tecnologias existentes, que proporcionam controles nunca vistos sobre a forma de se realizar o trabalho. Com o emprego de métodos que apontam para a individualização do trabalhador, a não existência de laços de afetividade e criando uma filosofia de vida a partir do trabalho para o aperfeiçoamento do trabalho. Isto se explica por conta de que a sobrevivência passou a ser a maior meta criada e buscada por meio do trabalho.

Este processo de reducionismo do trabalho humano inverteu a ordem valorativa da vida, uma vez que ela passou a ser pensada a partir do trabalho, o que pode ser constatado na prática com o processo contínuo de redução do tempo livre do trabalhador. Não se trata de trabalhar com causas e consequências, mas sim de forma dialética, dentro de uma dinâmica que se aperfeiçoa e aliena a cada vez mais aquele que trabalha.

A construção de formas de apropriação do trabalho pelo trabalhador, mediante núcleos de trabalho e ou cooperativas de trabalho, nos quais aquele que trabalha consiga identificar o seu trabalho no produto realizado pode se constituir em uma das alternativas para esta segunda via, na tentativa de resgatar a dignidade no trabalho, redesenhando uma nova estrutura social a partir de novas formas de organizações produtivas.

\section{REFERÊNCIAS}

ANTUNES, Ricardo. Adeus ao Trabalho? Campinas: Cortez, 1995.

Os sentidos do trabalho: ensaio sobre a afirmação e negação do trabalho. São Paulo: Boitempo, 1999.

ARON, R. As etapas do pensamento sociológico. São Paulo: M. Fontes, 1997.

BAUMAN, Z. Globalização: as conseqüências humanas. Rio de Janeiro: Zahar, 1999.

BOBBIO, Norberto. A era dos direitos. 9. ed. Rio de Janeiro: Campus, 1992.

BORON, Atílio A. Hegemonia e imperialismo no sistema internacional. In: BORON, Atílio A. (Org.). Nova hegemonia mundial: alternativas de mudança 
e movimentos sociais. Buenos Aires: Consejo Latinoamericano de Ciências Sociales, 2004.

BRAVERMAM, H. Trabalho e capitalismo monopolista. Rio de Janeiro: Zahar, 1980.

CANOTILHO, José Joaquim Gomes. Direito constitucional. Lisboa: Almedina, 2007.

CHAUI, Marilena. Introdução. In: LAFARGUE, P. O direito à preguiça. São Paulo: Hucitec, 2000.

CASTEL, Robert. As metamorfoses da questão social: uma crônica do salário. Rio de Janeiro: Vozes, 1998. Parte 7, p. 415-494.

COSTA, Achyles Barcelos e outros. A irracionalidade no debate público. Disponível em: $<\mathrm{http}: / /$ revistas.fee.tche.br/index.php/indicadores/article/ viewFile/1777/2146>. Acesso em 20 jan. 2000.

DE MASI, Domenico. O ócio criativo. Tradução Lea Manzi. Rio de Janeiro: Sextante, 2000.

DOWBOR, Ladislaw. Política Nacional de apoio ao desenvolvimento local. Disponível em: <http://dowbor.org/artigos.asp>. Acesso em 10 abr. 2009.

FREITAS, Juarez. Interpretação sistemática do direito. 4. ed. São Paulo: Malheiros, 2004.

GOERGEN, Pedro. Pós-Modernidade, ética e educação. Campinas: Autores Associados, 2001. (Coleção Polêmicas do Nosso Tempo; 79).

GRAU, Eros Roberto. A ordem econômica na Constituição de 1988. 10. ed. São Paulo: Malheiros, 2005.

GORZ, A. Adeus ao Proletariado: para além do socialismo. Rio de Janeiro: Forense Universitária, 1987.

GOUNET, Thomas. Fordismo e toyotismo na civilização do automóvel. São Paulo: Boitempo, 1999.

GRESPAN, Jorge. Karl Marx. São Paulo: Publifolha, 2008. 
HABERMAS, Jürgen. Teora de la accion comunicativa. Madrid: Taurus, 1998. v. 2.

HARVEY, David. Condição Pós-Moderna. 6. ed São Paulo: Loyola, 1996.

HAYEK, Friedrich A. O caminho da servidão. 2. ed São Paulo: Globo, 1977.

IANNI, Octávio. A era do globalismo. 3. Ed. Rio de Janeiro: Civilização Brasileira, 1977.

JAVILLIER, Jean-Claude. Manual de direito do trabalho. São Paulo: LTr, 1988.

HIFIKIN, Jeremy. O fim do emprego. São Paulo: Makron Books, 2007.

KURZ, R. O colapso da modernização. Tradução Karen E. Barbosa. São Paulo: Paz e Terra, 1992.

LAFARGUE, Paul. O direito à preguiça. Tradução J. Teixeira Coelho Netto. São Paulo: Hucitec, 1999.

LUCENA, Carlos. A humanidade, a natureza e o trabalho. Revista HISTEDBR On-line, Campinas, n. 24, p. 51-63, dez. 2006. Disponível em: $<$ http://www.histedbr.fae.unicamp.br/art05_24.pdf $>$. Acesso em: 15 jan. 2009.

MARTINS FILHO, Ives Gandra da Silva. Os Direitos sociais na Constituição (síntese de palestra). Disponível em: $<$ http://www.neofito.com.br/artigos/ art01/const23.htm>. Acesso em: 18 dez. 2008.

MELLO, A. F. Marx e a globalização. São Paulo: Boitempo, 1999.

MÉSZARÓS, I. Para além do capital. São Paulo: Boitempo EdUNICAMP, 2002.

. O poder da ideologia. São Paulo: Boitempo, 2004.

NUNES, Antõnio José Avelãs. Neloliberalismo e direitos humanos. Rio de Janeiro: Renovar, 2003.

. Teoria econômica e desenvolvimento econômico. Lisboa: Editorial Caminho, 1988. 
TORRES, Ricardo Lobo. Teoria dos direitos fundamentais. Rio de Janeiro: Renovar, 1999.

REALE, Miguel. Estudos de filosofia e ciência do direito. São Paulo: Saraiva, 1978.

VIEIRA, Oscar Vilhena. A Constituição e sua reserva de justiça. S. Paulo: Malheiros, 1999.

\title{
STUDIES ON THE PROCESS OF HUMAN LABOR DEVALUATION ACCORDING TO THE 21 $1^{\text {st }}$-CENTURY BUSINESS LOGIC
}

\begin{abstract}
From the study developed, it can be concluded that recent technological advances have forced men into a new work routine, more intense, drastically reducing the possibility of having free time. The trend is to generate a fragmented, insecure job, focused only on human survival and at odds with the constitutional principles, and in turn, with social rights, that foresee work that can contribute to reducing social inequalities, with the emancipation of men, while giving them conditions to exhibit their creativity and find themselves in the social environment as a performing agent. The term free work takes a new dimension, while being work that, contrary to the market logic, is enough to provide the worker not only survival or a precarious existence, but a constructive life. The criticism of the production logic must be able to create intervention mechanisms capable of restoring dignity at work.
\end{abstract}

KEYWORDS: Technological progress; Employment centralization; Decent work; Humanization at work.

\section{ESTUDIOS SOBRE EL PROCESO DE DESVALORIZACIÓN DEL TRABAJO HUMANO DE ACUERDO CON LA LÓGICA EMPRESARIAL DEL SIGLO XXI}

RESUMEN: Hecho el estudio, se ha concluido que los avances tecnológicos han impuesto al hombre una nueva rutina de trabajo, más intensa, reduciendo mucho la existencia de tiempo libre. La tendencia es la generación de un trabajo fragmentado, precario, vuelto solamente a la supervivencia humana, encontrándose en desacuerdo con los principios constitucionales y por su vez con los derechos sociales, que prevé un trabajo que puede contribuir con la reducción de las desigualdades sociales, con la emancipación del hombre, mientras le da condiciones de exponer su creatividad y de ubicarse en el medio social como agente realizador. La expresión trabajo libre toma nueva dimensión, siendo aquel trabajo que, 
contrariando la lógica del mercado, es suficiente para proporcionar al trabajador no sólo la supervivencia o la existencia precaria, pero una vida constructiva. La crítica a la lógica de la producción debe ser capaz de crear mecanismos de intervención capaces de restablecer la dignidad en el trabajo.

PALABRAS CLAVE: Avances tecnológicos; Centralización del trabajo; Dignidad en el trabajo; Humanización en el trabajo. 